\title{
Effect of several commercial rubbers as substrates for zinc oxide in the photocatalytic degradation of methylene blue under visible irradiation
}

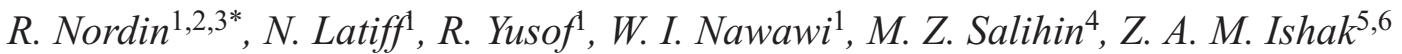 \\ ${ }^{1}$ Department of Chemistry, Faculty of Applied Sciences, Universiti Teknologi MARA, Perlis Branch, Arau Campus, \\ 02600 Arau, Perlis, Malaysia \\ ${ }^{2}$ Green and Functional Polymer Research Group, Universiti Teknologi MARA, 40450 Shah Alam, Selangor, Malaysia \\ ${ }^{3}$ Advanced Technology Training Center, Manpower Department, Ministry of Human Resource, 34600 Kamunting \\ Taiping, Perak, Malaysia \\ ${ }^{4}$ Center of Excellence Geopolymer and Green Technology, School of Materials Engineering, Universiti Malaysia Perlis, \\ 01007, P.O Box 77, D/A Pejabat Pos Besar, Kangar, Perlis, Malaysia \\ ${ }^{5}$ Science and Engineering Research Center, Universiti Sains Malaysia, Engineering Campus, 14300 Nibong Tebal, Pulau \\ Pinang, Malaysia \\ ${ }^{6}$ School of Materials and Mineral Resources Engineering, Universiti Sains Malaysia, Engineering Campus, 14300 Nibong \\ Tebal, Pulau Pinang, Malaysia
}

Received 11 July 2019; accepted in revised form 8 February 2020

\begin{abstract}
A new approach of mechanical preparation of photocatalyst zinc oxide ( $\mathrm{ZnO})$ /rubbers from four types of rubbers: styrene butadiene rubber (SBR), ethylene propylene diene monomer (EPDM), natural rubber (NR), and epoxidized natural rubber (ENR) with $50 \%$ epoxidation is presented. This technique is simple, fast and cost effective as $\mathrm{ZnO} /$ rubbers were mechanically mixed using conventional two-roll mill at $27^{\circ} \mathrm{C}$ for $10 \mathrm{~min}$ and compressed into flat sheet. The characteristics of photocatalyst were studied by X-ray diffraction (XRD), Fourier-transform infrared spectroscopy (FTIR), ultraviolet-visible spectroscopy (UV-Vis) and field emission scanning electron microscope (FESEM). The photocatalytic activity of ZnO/rubbers was evaluated using methylene blue (MB) as a model pollutant under visible light for $300 \mathrm{~min}$. The photocatalytic degradation efficiency of $\mathrm{ZnO} / \mathrm{SBR}$ is nearly as good as that of $\mathrm{ZnO}$ powder (87.32\%) compared to $\mathrm{ZnO} / \mathrm{NR}$, ZnO/EPDM and $\mathrm{ZnO} / \mathrm{ENR}$. This is due to the highest index of conjugated carbon-carbon bond of SBR and hydrogen bonding between $\mathrm{ZnO}$ and SBR. The formation of hydrogen bonding was confirmed by FTIR and reduction of energy band gap of ZnO/SBR. The photocatalytic degradation of $\mathrm{MB}$ with $\mathrm{ZnO} / \mathrm{SBR}$ was could be fitted by pseudo-first-order kinetics of the Langmuir-Hinshelwood model.
\end{abstract}

Keywords: rubber, zinc oxide, methylene blue, photocatalytic, visible irradiation

\section{Introduction}

Semiconductor-assisted photocatalytic degradation of organic dyes has attracted considerable attention owing to its high effectiveness in complete oxidation and mineralization of harmful organics using solar light irradiation, which is free and inexhaustible [1]. Zinc oxide ( $\mathrm{ZnO})$ is one of the n-type semiconductors with a wide band gap $(3.3 \mathrm{eV})$ and large excitation binding energy $(60 \mathrm{meV})$ [2]. $\mathrm{ZnO}$ showed excellent results on photocatalytic degradation of methylene blue (MB) and methyl orange (MO) dyes [3-5]. The performance of $\mathrm{ZnO}$ is strongly associated with the nature of its electronic structure $[6,7]$. 


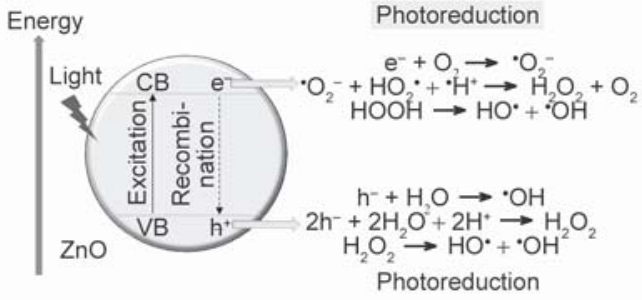

Figure 1. Photocatalytic degradation of organic pollutants by $\mathrm{ZnO}$.

The underlying science of photocatalysis of $\mathrm{ZnO}$ is shown in Figure 1. As the photon with an equivalent or more energy hits the surface of the $\mathrm{ZnO}$, an electron jumps from the conduction band to the valance band, thus creating an electron-hole pair. These photoinduced electrons and holes move separately to the surface of the $\mathrm{ZnO}$ and react with $\mathrm{O}_{2}$ and $\mathrm{H}_{2} \mathrm{O}$. This leads to the formation of hydroxyl radical $(\cdot \mathrm{OH})$, superoxide radical anions $\left(\cdot \mathrm{O}_{2}\right)$ and hydroperoxyl radicals $(\cdot \mathrm{OOH})[8]$.

A conventional method of the using powdered $\mathrm{ZnO}$ in aqueous solution is highly effective in dye degradation due to a high ratio of surface to volume of water. However, because of the small particle sizes of $\mathrm{ZnO}$ suspended in water clogs filter membranes, penetrates through porous filter materials and forms slurry therefore filtration process is needed $[9,10]$. Hence, several efforts have been made by previous researchers to coat photocatalyst onto supporting materials such as glass [11], metal [12], and natural rubber latex [13].

Yet, the synthesized $\mathrm{ZnO}$ on these supports still sinks in solution without agitation, thus hinders the support from light exposure and decreases the efficiency of degradation [14]. The researchers attempted to solve the problem by developing a suitable support that make photocatalyst float on the surface of water. New support materials such as expanded perlite [15], chitosan [14], and natural rubber latex [13] were reported. However, very limited of works were reported on the use of dry rubber (DR) as a substrate for photocatalytic degradation activities. DR strikes the interest in this study due to its versatility, locally availability, light-weight, non-toxic properties, easily processability, and low price.

Numerous techniques including dip coating [16], solution casting [17], chemical vapor deposition (CVD) [18], and electrophoretic deposition [19] have been employed to coat the semiconductor $(\mathrm{ZnO})$ onto the supporting materials. Noticeably, these techniques have many disadvantages such as: (i) sintering step is necessary, (ii) the removal of organic solvent has negative impact on the environment, (iii) high cost, and (iv) involve the presence of corrosive gases [2022]. To overcome the problems, this study attempts preparing the $\mathrm{ZnO} /$ rubber sheets via mechanical processing method. To the best of our knowledge, this method has never been used for the preparation of photocatalyst sheets or films in photocatalytic study. This advantageous method is simple, solvent-free, time-saving, and most importantly, strong enough to hold the $\mathrm{ZnO}$ powder.

The aim of this work is to investigate the photocatalytic degradation of methylene blue (MB) under visible light irradiation with $\mathrm{ZnO} / \mathrm{SBR}, \mathrm{ZnO} / \mathrm{NR}$, $\mathrm{ZnO} / \mathrm{EPDM}$, and $\mathrm{ZnO} / \mathrm{ENR}$ photocatalyst sheets prepared via mechanical processing method. The type of substrates used may provide potential supporting materials that are not only maximize the utilization of light but also enhance the oxygenation of the photocatalyst, due to their floating ability.

\section{Experimental}

\subsection{Materials}

Styrene butadiene rubber (SBR) 1502 with styrene content of 23.5\%, Standard Malaysia Rubber L (NR), ethylene-propylene diene monomer (EPDM) - Keltan 9650Q, and epoxidized natural rubber (ENR) containing 50\% epoxidation were supplied by Malaysian Rubber Board (MRB), Selangor (Malaysia). The

a)

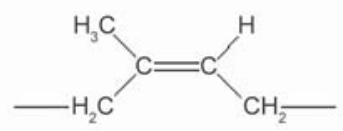

b)

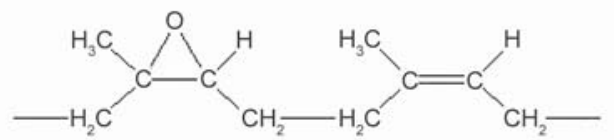

c)
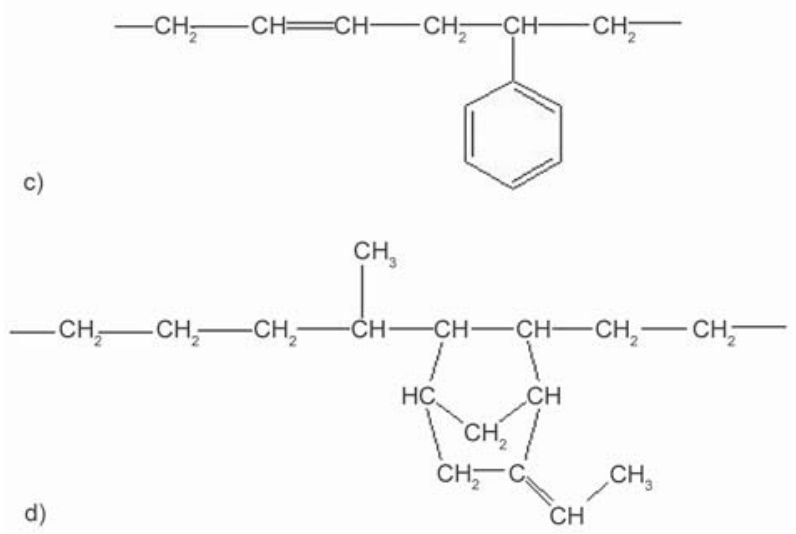

Figure 2. Polymeric structure of (a) NR, (b) ENR, (c) SBR, and (d) EPDM. 
polymeric structure of NR, ENR, SBR, and EPDM is shown in Figure 2.

$\mathrm{ZnO}$ (99.8\% purity) was purchased from CHEMETAL (Malaysia) Sdn. Bhd., Selangor (Malaysia) and methylene blue (MB) $(373.88 \mathrm{~g} / \mathrm{mol})$ was obtained from HmbG Chemicals, Hamburg (Germany). In this study, the particle sizes of $\mathrm{ZnO}$ were in the range of 38 $90 \mu \mathrm{m}$.

\subsection{Preparation of $\mathrm{ZnO} /$ rubbers}

The preparation of $\mathrm{ZnO} /$ rubbers at a ratio of 80:20 [wt $\%$ ] was carried out on laboratory sized tworoll mill $(160 \times 320 \mathrm{~mm})$ model K-160 (China) friction ratio of rollers 1:1.4 for about $10 \mathrm{~min}$. The samples were compression molded into a $0.54 \mathrm{~mm}$ thick using hydraulic press at 150 bar at $27^{\circ} \mathrm{C}$ for $2 \mathrm{~min}$. The appearance, flexibility, elasticity and floatability of $\mathrm{ZnO} /$ rubber are in shown Figure 3.

\subsection{X-ray diffraction (XRD) spectroscopy}

$\mathrm{XRD}$ was used to determine the crystal structure of $\mathrm{ZnO}$ using Bruker AXS GmbH D2 Phaser X-ray diffractometer (Karlsruhe-Germany) equipped with $\mathrm{Cu} \mathrm{K} \alpha$ irradiation at $\lambda=1.5406 \AA$, generated at $30 \mathrm{kV}$ and $10 \mathrm{~mA}$. The scanning $2 \theta$ range is 10 to $80^{\circ}$.

\subsection{Fourier transform infra-red (FTIR) spectroscopy}

Attenuated total reflection Fourier transform infrared spectroscopy (ATR-FTIR) (Perkin Elmer Spectrum One Series, United States of America) is used to

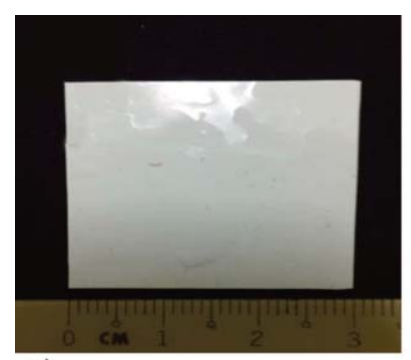

a)

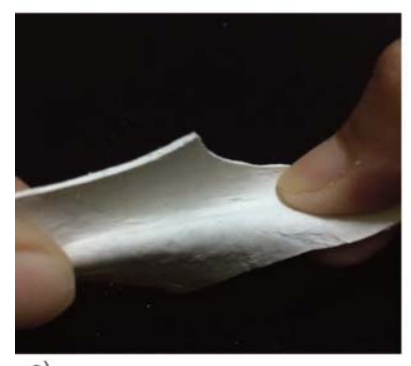

c)

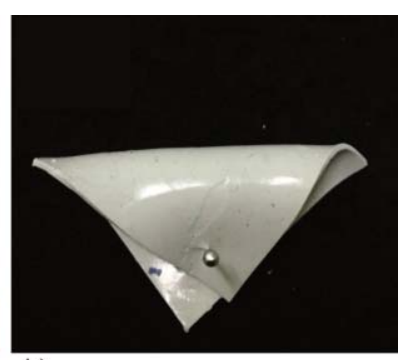

b)

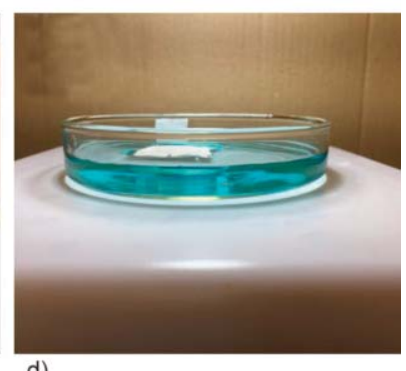

d)
Figure 3. Photographs of the (a) appearance, (b) flexibility, (c) elasticity, and (d) floatability of $\mathrm{ZnO} /$ rubber. evaluate structural variations on the samples. For each spectrum, 32 consecutive scans with $4 \mathrm{~cm}^{-1}$ resolutions in the range of $4000-450 \mathrm{~cm}^{-1}$ were recorded.

\subsection{UV-Visible (UV-Vis) spectroscopy}

Optical transmittance and absorbance spectral were measured on Varian Cary ${ }^{\circledR} 50$ UV-Vis spectrophotometer (Australia) equipped with quartz cuvette. In order to acquire UV-Vis spectra, the samples were dissolved in tetrahydrofuran (THF) at $0.1 \mathrm{~g} \cdot \mathrm{l}^{-1}$. THF was selected due to its properties of transparence, easily dissolves rubber with a cut-off wavelength at $212 \mathrm{~nm}$ [23].

\subsection{Field emission scanning electron microscopy (FESEM)}

The morphologies of the $\mathrm{ZnO}$ powder were investigated with a Hitachi SU8020 FESEM (Japan). The $\mathrm{ZnO}$ was mounted on aluminum stubs and sputtercoated with a thin layer of gold to improve image processing during examination.

\subsection{Photocatalytic degradation of methylene blue (MB)}

The photocatalytic degradation was investigated using MB solution as a model pollutant under visible light (7.5 W Vis-LED lamp, Philips). Photocatalytic degradation was carried out in a 29.611 closed rectangular compartment $(31.9 \mathrm{~cm}$ height, $34.9 \mathrm{~cm}$ length and $26.6 \mathrm{~cm}$ width) equipping with an exhaust fan in a photoreactor. About $2 \mathrm{~g}$ square shaped $(3 \times 3 \mathrm{~cm})$ photocatalyst samples were set afloat in a petri dish containing $60 \mathrm{~mL} \mathrm{MB}$ solution $\left(1.0 \mathrm{mg} \cdot \mathrm{l}^{-1}\right)$. The solutions were stirred for $15 \mathrm{~min}$ at $100 \mathrm{rpm}$ in the dark to achieve adsorption-desorption equilibrium prior to testing. The photoreactor was then irradiated with constant stirring and $5 \mathrm{ml}$ of MB solution was collected at regular time intervals (20 min) and centrifuged ( $6000 \mathrm{rpm}$ for $10 \mathrm{~min}$ ). The distance between the petri dish and Vis lamp was fixed to $10 \mathrm{~cm}$. The concentration of MB was calculated through a calibration curve of the absorbance at $\lambda_{\max }=661 \mathrm{~nm}$ using portable UV-Vis spectrophotometer $(\mathrm{HACH}$ DR 1900, United States of America). The photocatalytic degradation $(D \%)$ of $\mathrm{MB}$ was calculated from Equation (1):

Photocatalytic degradation:

$D \%=\frac{C_{0}-C_{\mathrm{t}}}{C_{0}} \cdot 1000$ 
where $C_{0}$ is the initial concentration of $\mathrm{MB}\left[\mathrm{mg} \cdot \mathrm{l}^{-1}\right]$ and $C_{\mathrm{t}}$ is concentration of $\mathrm{MB}\left[\mathrm{mg} \cdot \mathrm{l}^{-1}\right]$ at irradiation time $(t)$. The kinetic of degradation of MB was determined using the Langmuir-Hinshelwood model based on pseudo-first-order (Equation (2)) and pseudo-second-order (Equation (3)) [5] respectively:

$$
\begin{aligned}
& \ln \frac{C_{0}}{C_{\mathrm{t}}}=k_{1} t \\
& \frac{1}{C_{\mathrm{t}}}=\frac{1}{C_{0}+k_{2} t}
\end{aligned}
$$

The pseudo-first- and second-order rate constants, $k_{1}$ and $k_{2}$ were calculated from the slope of $\ln \left(C_{0} / C_{\mathrm{t}}\right)$ and $1 / C_{\mathrm{t}}$ versus irradiation time $(t)$, respectively.

\section{Results and discussion}

\subsection{Internal Structure of $\mathrm{ZnO}$}

The internal crystalline structure in $\mathrm{ZnO}$ was indicated by the XRD patterns as shown in Figure 4. The sharp and intense diffraction peaks were observed at $2 \theta$ values $=31.99,34.66,36.48,47.74,56.80,63.05$, 68.15 , and $69.28^{\circ}$ which correspond to (100), (002), (101), (102), (110), (103), (112), and (201) reflection planes, respectively. According to Joint Committee on Powder Diffraction Standard (JCPDS), this spectrum clearly indicates the presences of good crystalline hexagonal wurtzite phase of $\mathrm{ZnO}$ structure (JCPDS card no: 36-1451). No impurity peak related to any other phases of $\mathrm{Zn}$ such as $\mathrm{Zn}(\mathrm{OH})_{2}$, $\mathrm{Zn}_{5}(\mathrm{OH})_{6} \mathrm{CO}_{3}$ or $\mathrm{Zn}$-derivative complexes were observed in XRD pattern. Our XRD results, thus confirmed the purity of $\mathrm{ZnO}$ powder.

\subsection{Fourier transform infrared (FTIR) spectroscopy}

The FTIR spectra of $\mathrm{ZnO}$, virgin rubbers, and $\mathrm{ZnO} /$ rubbers are presented in Figure 5. The characteristic

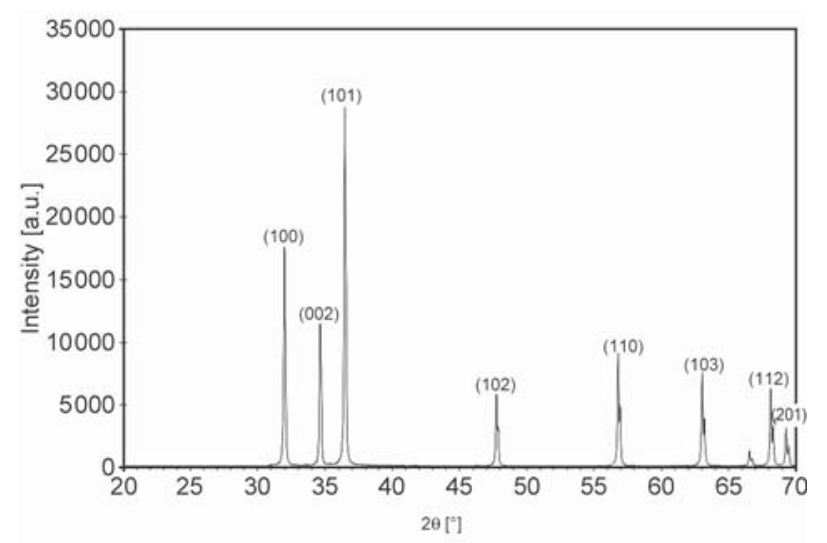

Figure 4. XRD pattern of $\mathrm{ZnO}$ powder. peaks and functional groups are consistent with the previous reports; $\mathrm{ZnO}$ [24] and virgin rubber (SBR [25], NR [26], EPDM [27], and ENR [28]). By comparing the changes between $\mathrm{ZnO}$, virgin rubber and $\mathrm{ZnO} /$ rubber spectra (Figure 5), it is observed that the intensities of prominent peaks such as conjugated $\mathrm{C}=\mathrm{C}$ (aliphatic $\left[1641 \mathrm{~cm}^{-1}\right]$ and aromatic $\left[910 \mathrm{~cm}^{-1}\right]$ ), and cyclic $\mathrm{C}-\mathrm{O}-\mathrm{C}\left(875 \mathrm{~cm}^{-1}\right)$ were slightly decreased from designated peaks, thereby, indicating the possibility of changes in index intensity of $\mathrm{C}=\mathrm{C}$ (aliphatic and aromatic) and $\mathrm{C}-\mathrm{O}-\mathrm{C}$ peak. The index intensity of conjugated $\mathrm{C}=\mathrm{C}$ peak was used to evaluate exciton sites, while $\mathrm{C}-\mathrm{O}-\mathrm{C}$ peak for ring opening reaction. The $\mathrm{CH}_{2}$ bond is selected internal reference because it: (i) remain stable below $100^{\circ} \mathrm{C}$ [29] and (ii) exists in SBR, NR, EPDM and ENR. The intensity index ratio $\left(I_{\mathrm{x}}\right)$ of conjugated $\mathrm{C}=\mathrm{C}$ and $\mathrm{C}-\mathrm{O}-\mathrm{C}$ band were calculated us using Equation (4):

$I_{\mathrm{x}}=\frac{A_{\mathrm{x}}}{A_{\mathrm{y}}}$

$A_{\mathrm{x}}$ is the absorbance of the selected band, while $A_{\mathrm{y}}$ is the reference absorption of $\mathrm{CH}_{2}\left(1445 \mathrm{~cm}^{-1}\right)$. Table 1 shows the quantified index of conjugated $\mathrm{C}=\mathrm{C}$ and $\mathrm{C}-\mathrm{O}-\mathrm{C}$ from FTIR spectra of $\mathrm{ZnO}$, virgin rubbers and $\mathrm{ZnO} /$ rubbers. The index of conjugated $\mathrm{C}=\mathrm{C}$ of virgin rubbers is not affected with the incorporation of $\mathrm{ZnO}$, which indicates: (i) no chemical reaction occurred between aliphatic or aromatic $\mathrm{C}=\mathrm{C}$ and $\mathrm{ZnO}$ and (ii) available for electron excitation. Meanwhile, the $\mathrm{C}-\mathrm{O}-\mathrm{C}$ index for ENR decreased slightly from index ratio of 2.0 to 1.9 with the incorporation of $\mathrm{ZnO}$ due to the partial ring opening reaction. However, SBR with or without incorporation of $\mathrm{ZnO}$ was proved to have more conjugated $\mathrm{C}=\mathrm{C}$ index compared to NR, EPDM and ENR.

Table 1. Values of $\mathrm{C}=\mathrm{C}$ and $\mathrm{C}-\mathrm{O}-\mathrm{C}$ index of $\mathrm{ZnO} /$ rubber

\begin{tabular}{|c|c|c|c|c|c|}
\hline Bond & $\begin{array}{c}A_{\mathrm{X}} \\
{\left[\mathrm{cm}^{-1}\right]}\end{array}$ & Samples & $\begin{array}{c}\text { Index } \\
\text { ratio }\end{array}$ & Samples & $\begin{array}{c}\text { Index } \\
\text { ratio }\end{array}$ \\
\hline $\begin{array}{l}-\mathrm{CH}=\mathrm{CH} \\
\text { (aliphatic) }\end{array}$ & 1641 & \multirow{2}{*}{ SBR } & 1.9 & \multirow{2}{*}{$\mathrm{ZnO} / \mathrm{SBR}$} & 1.9 \\
\hline $\begin{array}{l}-\mathrm{C}=\mathrm{CH} \\
\text { (aromatic) }\end{array}$ & 965 & & 2.1 & & 2.1 \\
\hline $\begin{array}{l}-\mathrm{CH}=\mathrm{CH} \\
\text { (aliphatic) }\end{array}$ & 1641 & NR & 1.9 & $\mathrm{ZnO} / \mathrm{NR}$ & 1.9 \\
\hline $\begin{array}{l}=\mathrm{CH}-\mathrm{CH} 2- \\
\text { (aliphatic) }\end{array}$ & 875 & EPDM & 1.9 & $\mathrm{ZnO} / \mathrm{EPDM}$ & 1.9 \\
\hline $\begin{array}{l}-\mathrm{CH}=\mathrm{CH} \\
\text { (aliphatic) }\end{array}$ & 1641 & \multirow{2}{*}{ ENR } & 1.9 & \multirow{2}{*}{$\mathrm{ZnO} / \mathrm{ENR}$} & 1.9 \\
\hline $\begin{array}{l}\mathrm{C}-\mathrm{O}-\mathrm{C} \\
\text { (cyclic) }\end{array}$ & 875 & & 2.0 & & 1.9 \\
\hline
\end{tabular}
composites compared to virgin rubbers. 

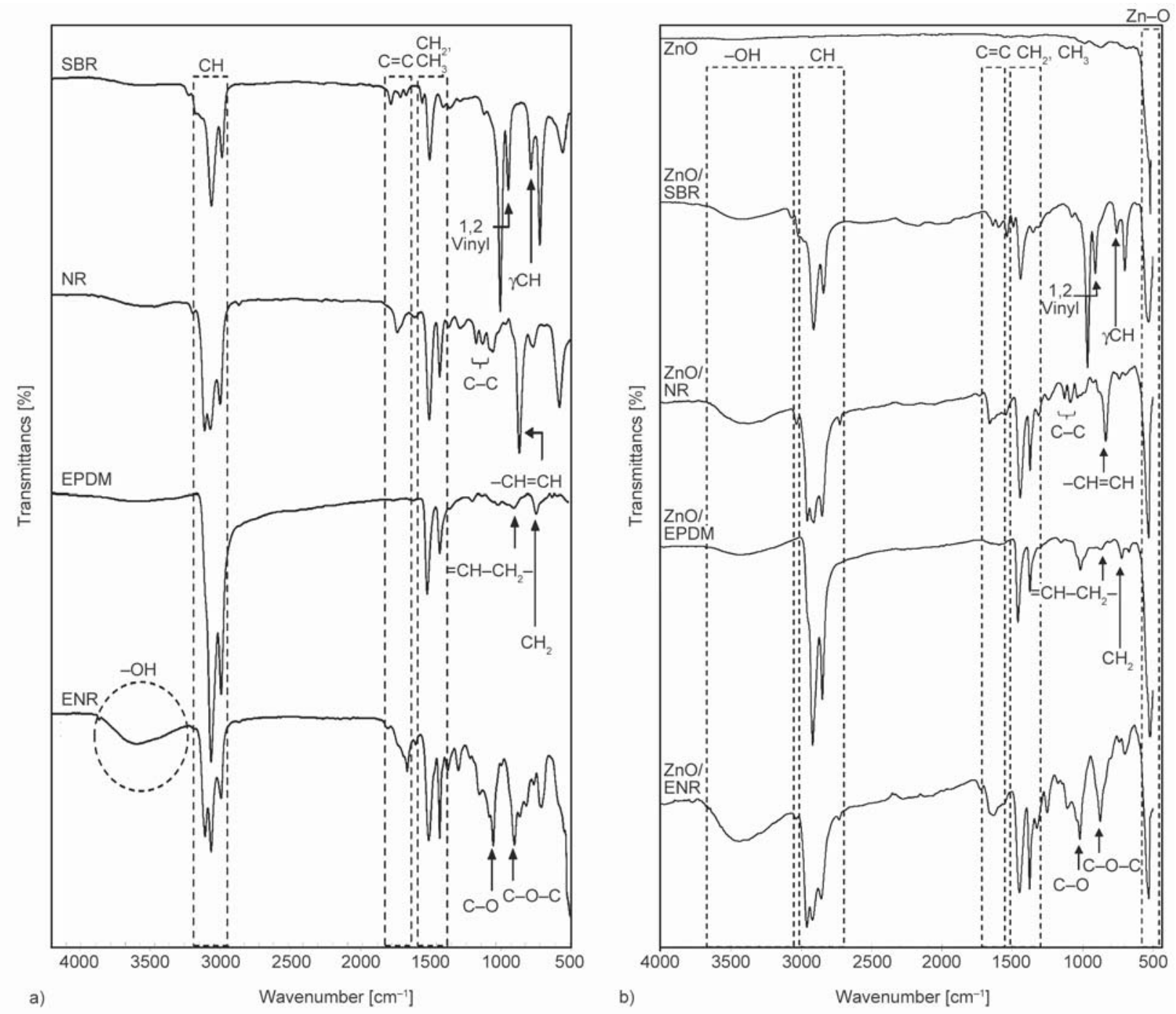

Figure 5. FTIR spectra of (a) virgin rubbers and $\mathrm{ZnO}$, (b) $\mathrm{ZnO}$ /rubbers.

\subsection{Ultraviolet - visible (UV-Vis) spectroscopy}

Figure 6 shows the UV-Vis absorption spectra of virgin rubbers, $\mathrm{ZnO}$, and $\mathrm{ZnO}$ /rubbers. The absorption edge for $\mathrm{ZnO}$ and virgin rubbers are within 327 $335 \mathrm{~nm}$. These results are consistent with the previous reports $[28,30,31]$. The incorporation of $\mathrm{ZnO}$ into rubbers, however, resulting in two absorption edges in between of $360-390$ and $460-510 \mathrm{~nm}$. It is worth mentioning over here that the absorption edges of $\mathrm{ZnO} /$ rubbers were extended to higher wavelengths compared to bare $\mathrm{ZnO}(335 \mathrm{~nm})$ and virgin rubbers due to the aforementioned interaction (hydrogen bonding) of $\mathrm{ZnO}$ and rubbers. Mahmood et al. [28] also reported similar absorption spectra. The lower absorption edge is corresponding to $\pi-\pi^{*}$ transition of $\mathrm{C}=\mathrm{C}$ of rubber macromolecules and the higher absorption edge is assigned to the $n-\pi *$ transition of the lone pair oxygen atom that forms a hydrogen bond.
Further analysis on absorption coefficient of $\mathrm{ZnO} /$ rubbers are required in order to understand the effect different types of rubbers. The molar absorptivity coefficient $(\varepsilon)$ is associated with the strong absorption region of the samples which is calculated from absorbent $(A)$ and path length (l) Equation (5):

$\varepsilon=2.303 \frac{A}{l}$

derived from Beer Lambert Law.

The optical band gap of all samples is calculated using Tauc relation [32] as shown in Equation (6):

$\varepsilon=\frac{B\left(h v-E_{\mathrm{g}}\right)^{\mathrm{n}}}{h v}$

where $B$ is a constant, $h v$ is the energy of incident photons, $E_{\mathrm{g}}$ is the energy band gap and exponent $n$ is a value that depends on the type the transition having values of $0.5,1.5,2$, and 3 corresponding to 

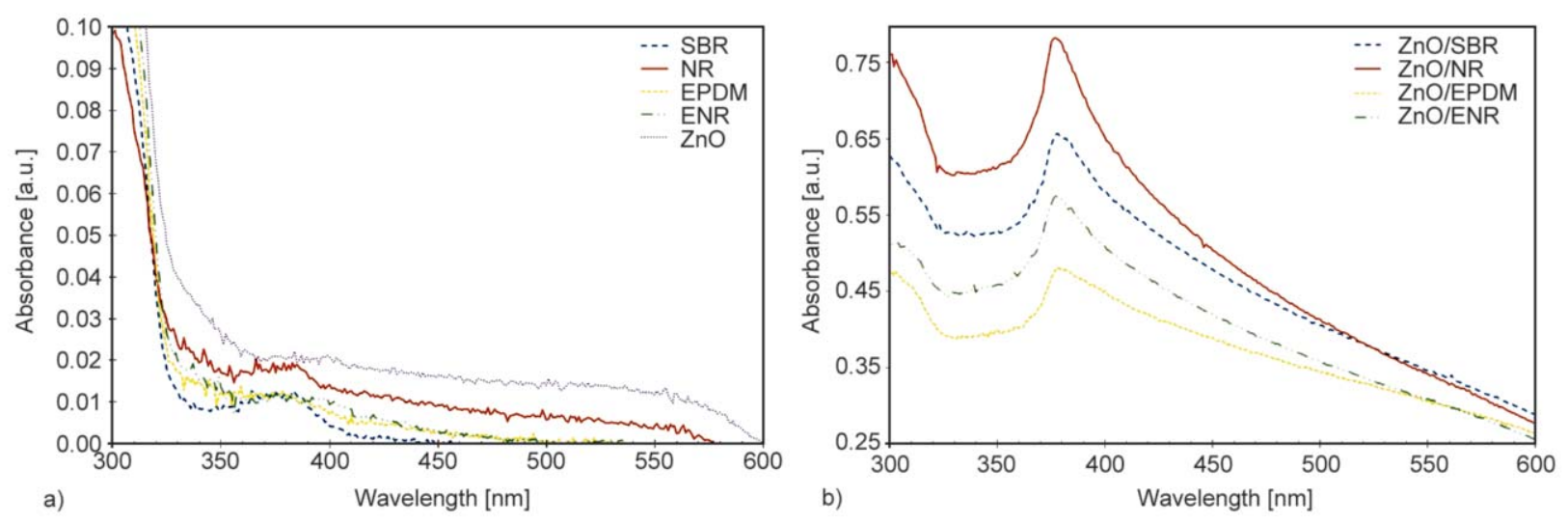

Figure 6. Variation of molar absorptivity coefficient of (a) virgin rubbers and $\mathrm{ZnO}$, (b) $\mathrm{ZnO}$ /rubbers as a function of wavelength.

allowed direct, forbidden direct, allowed indirect and forbidden indirect transitions, respectively [32]. Figure 7 show the variation of $(\varepsilon h v)^{1 / n} v s$. photon energy, $h v$ for virgin rubber, $\mathrm{ZnO}$ and $\mathrm{ZnO} /$ rubbers with $\mathrm{n}$ values of 0.5 , and 2 , respectively. Allowed direct and indirect band gaps of virgin rubbers, $\mathrm{ZnO}$, and $\mathrm{ZnO} /$ rubbers are listed in Table 2. The direct band gap energy of $\mathrm{ZnO}(3.82 \mathrm{eV})$ is slightly higher compared to the reported value by Lavand and Malghe

Table 2. The variation of band gap energy for all samples.

\begin{tabular}{|l|c|c|c|}
\hline \multicolumn{1}{|c|}{ Samples } & $\begin{array}{c}\text { Direct energy } \\
\text { band gap } \\
{[\mathbf{e V}]}\end{array}$ & $\begin{array}{c}\text { Indirect energy } \\
\text { band gap } \\
{[\mathbf{e V}]}\end{array}$ & $\boldsymbol{N}^{*}$ \\
\hline $\mathrm{SBR}$ & - & 3.68 & $2 / 3$ \\
\hline $\mathrm{NR}$ & - & 3.55 & $2 / 5$ \\
\hline $\mathrm{EPDM}$ & - & 3.70 & $1 / 8$ \\
\hline $\mathrm{ENR}$ & - & 3.70 & $1 / 5$ \\
\hline $\mathrm{ZnO}$ & 3.82 & - & - \\
\hline $\mathrm{ZnO} / \mathrm{SBR}$ & 2.72 & 2.68 & $2 / 3$ \\
\hline $\mathrm{ZnO} / \mathrm{NR}$ & 2.85 & 2.94 & $2 / 5$ \\
\hline $\mathrm{ZnO} / \mathrm{EPDM}$ & 2.52 & 3.00 & $1 / 8$ \\
\hline $\mathrm{ZnO} / \mathrm{ENR}$ & 2.68 & 2.88 & $1 / 5$ \\
\hline
\end{tabular}

${ }^{*} N$ : Number of carbon atoms that form conjugated carbon-carbon bond per number of carbon in repeating units of virgin rubbers

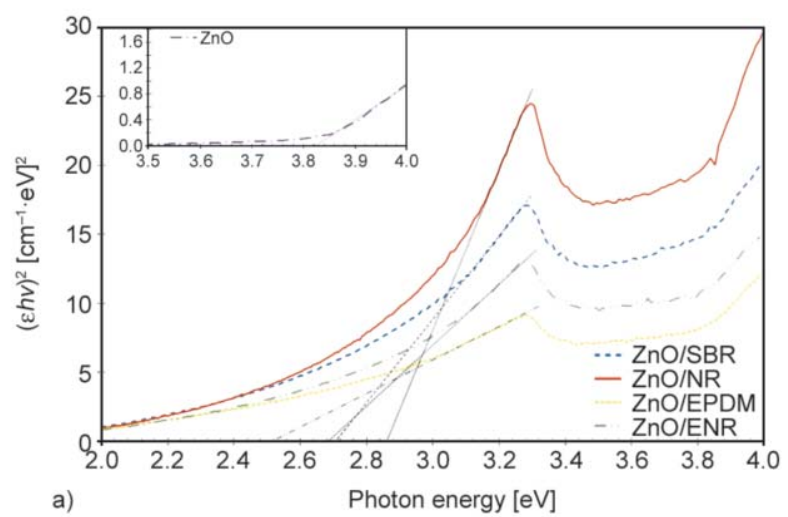

[24]. This is due to the combination effect of quantum confinement effect as a result of agglomeration [32] and different shapes (e.g. acicular, square, rod, cubic and hexagonal-like) of $\mathrm{ZnO}$ as shown in Figure 8 . Low indirect band gap energy of virgin rubbers is associated with slow and inefficient electron excitation especially at low temperature [33]. However, when the $\mathrm{ZnO}$ is incorporated in rubbers, two band gap energies were obtained corresponding to direct

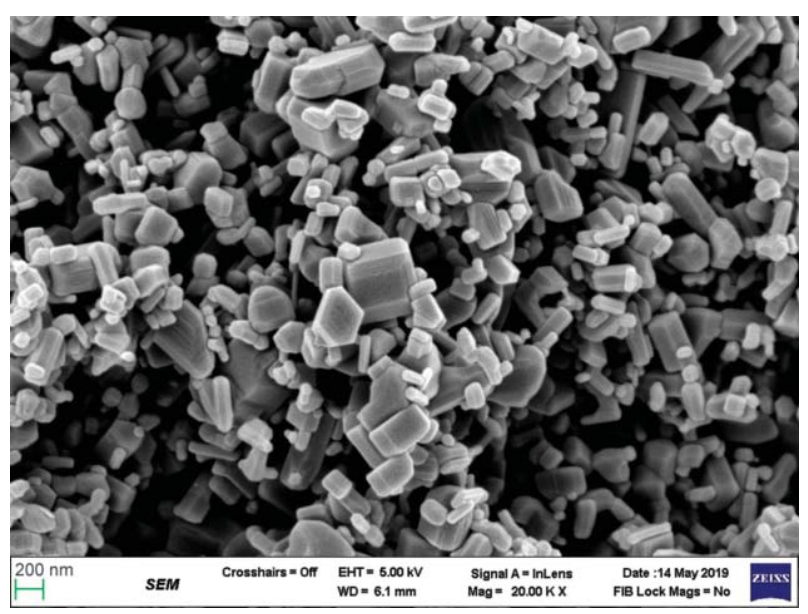

Figure 8. Micrograph images of $\mathrm{ZnO}$ powder.

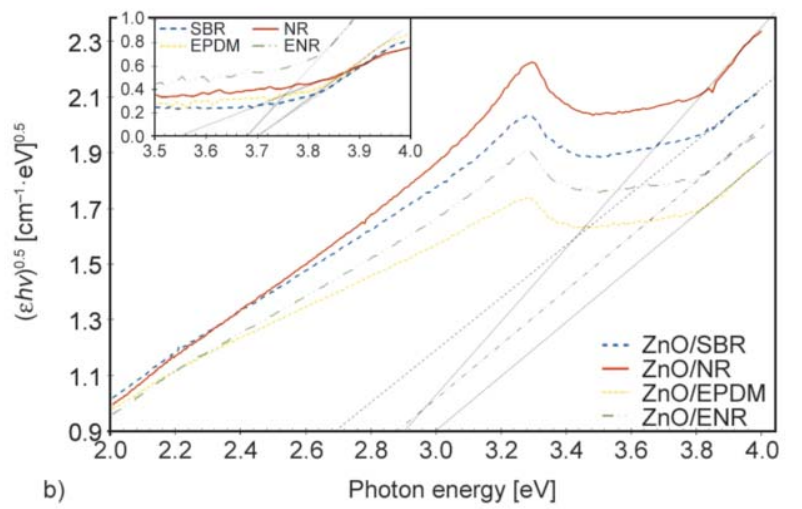

Figure 7. Variation of (a) $(\varepsilon h v)^{2}$ and (b) $(\varepsilon h v)^{0.5}$ for $\mathrm{ZnO}$ and virgin rubbers as a function of photon energy, $h v$. 
and indirect electron excitation. Interestingly, the direct and indirect band gap energies of $\mathrm{ZnO}$ /rubbers are lower than $\mathrm{ZnO}$ and virgin rubbers. This is due to the various degree on intensity of conjugated carbon either aliphatic and or aromatic of $\mathrm{ZnO}$-rubber as shown in Table 1 .

\subsection{Photocatalytic activity}

The change in the concentration of MB during photocatalytic and absorption of $\mathrm{ZnO}$, virgin rubbers and $\mathrm{ZnO} /$ rubbers after $300 \mathrm{~min}$ is presented in Figure 9. $\mathrm{ZnO}$ shows the highest removal of $\mathrm{MB}$ followed by $\mathrm{ZnO} /$ rubbers and virgin rubbers. This is due to its large surface area which further enhanced surface reactivity [34]. For virgin SBR, notable reduction of MB concentration may be attributed to the physisorption process. The incorporation of $\mathrm{ZnO}$ into rubbers improved the degradation of MB. The possible reason for this result can be ascribed to the role of $\mathrm{Zn}-\mathrm{OH}-\mathrm{C}$ hydrogen bonds in $\mathrm{ZnO} /$ rubbers that provide an ultrafast pathway for the charge transfer. Jin et al. [35] stated that this phenomenon happened due to: (i) hydrogen bonds are shorter than van der Waals junctions, and (ii) the inner electric field formed at the two ends of the hydrogen bond $\mathrm{ZnO}$ and rubbers). Among them, $\mathrm{ZnO} / \mathrm{SBR}$ shows a significant reduction of $\mathrm{MB}$ concentration closer to the percentage of $\mathrm{ZnO}$. The obtained results were correlated with the quantitative analysis of FTIR which revealed that SBR has more of the conjugated carboncarbon bond available compared to ENR, NR, and EPDM. According to Alkhatib et al. [36] conjugated carbon-carbon bond acts as photosensitive sites that can effectively enhance absorption and electron donor. The narrowed band gap of $\mathrm{ZnO} /$ rubbers could also be a factor that leads to the effective degradation

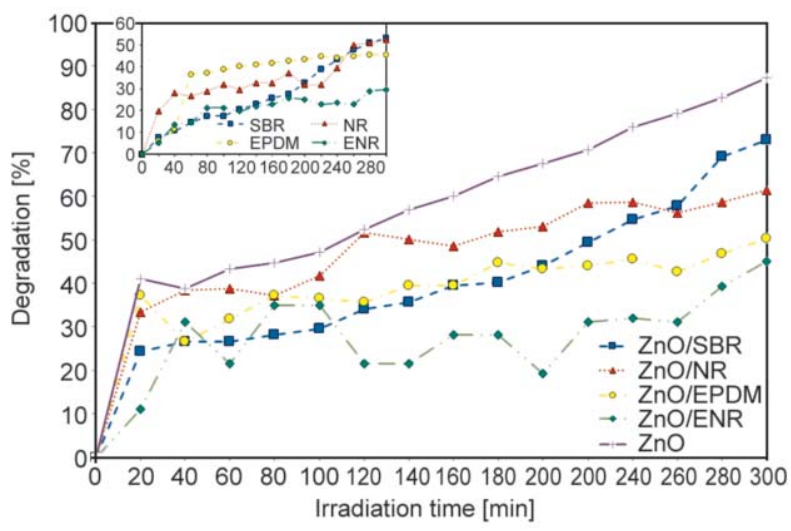

Figure 9. Relationship between equilibrium of degradation of $\mathrm{MB}$ after $300 \mathrm{~min}$ for $\mathrm{ZnO}$ composites. of MBs which is in accordance with the UV-Vis analysis (Figures 6 and 7). The reduction of band gap energies $\left(E_{\mathrm{g}}<3.3 \mathrm{eV}\right)$ causes the photoresponse of $\mathrm{ZnO} /$ rubbers broaden under visible light exposure. When light strikes the $\mathrm{ZnO} /$ rubbers sheet with sufficient energy, the electron-hole pairs are generated [36]. At the same time, the adhesion properties of rubber further enhanced the degree of MB dyes absorption onto the surface of $\mathrm{ZnO} /$ rubbers. Therefore, SBR is more suitable to be used as a substrate compared to ENR, NR and EPDM.

\subsection{Kinetics of the photocatalytic activity}

Photocatalytic kinetic degradation of MB fits to the pseudo first order equation of Langmuir-Hinshelwood model for semiconductor/rubber [5-9]. However, for confirmation, pseudo second order equation was also used to evaluate the rate of degradation of MB. A linear regression plots of pseudo first and second order for virgin rubbers, $\mathrm{ZnO}$ and $\mathrm{ZnO}$ /rubbers are given in Figures 10 and 11, respectively. The rate of degradation and correlation coefficients $\left(R^{2}\right)$ in Table 3 were obtained from Figures 10 and 11. Fine

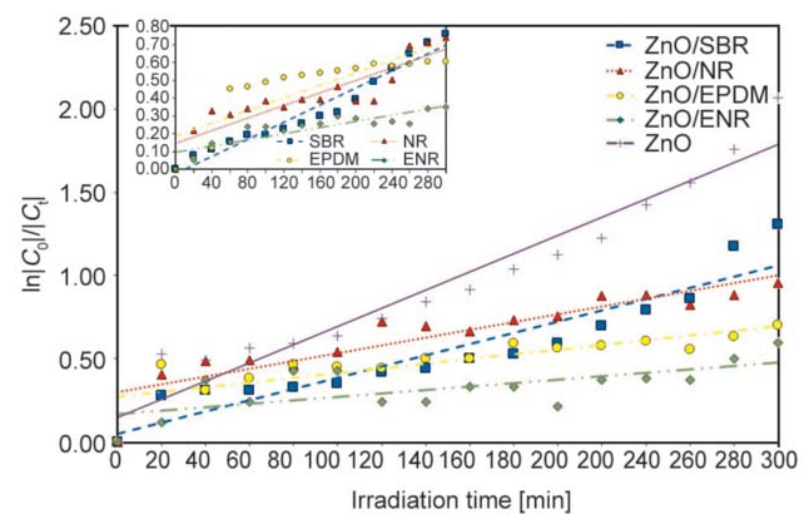

Figure 10. The plot of $\ln \left(C_{0} / C_{\mathrm{t}}\right)$ versus irradiation time for $\mathrm{ZnO}$ composites with different rubbers.

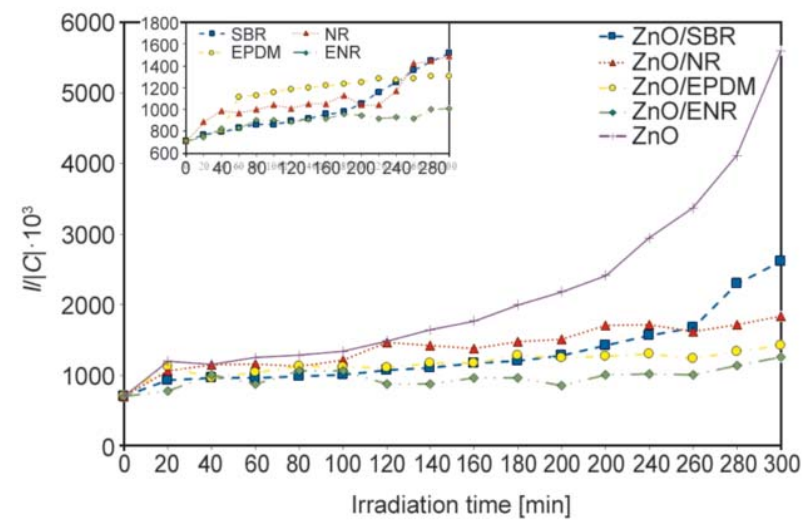

Figure 11. The plot of $\left(1 / C_{\mathrm{t}}\right)$ versus irradiation time for $\mathrm{ZnO}$ composites with different rubbers. 
Table 3. The pseudo-first and -second-order rate constants and correlation coefficients for photocatalytic degradation of MB for all samples.

\begin{tabular}{|l|c|c|c|c|}
\hline \multirow{2}{*}{ Samples } & \multicolumn{2}{|c|}{ Pseudo-first order } & \multicolumn{2}{c|}{ Pseudo-second order } \\
\cline { 2 - 5 } & $\begin{array}{c}\boldsymbol{k}_{\text {app }}, \boldsymbol{k}_{\mathbf{1}} \\
{\left[\mathbf{m i n}^{-1}\right]}\end{array}$ & $\boldsymbol{R}^{\mathbf{2}}$ & $\begin{array}{c}\boldsymbol{k}_{\text {app }}, \boldsymbol{k}_{\mathbf{2}} \cdot \mathbf{1 0} \\
{\left[\mathbf{1} \cdot \mathbf{m g}^{-\mathbf{1}} \cdot \mathbf{m i n}^{-\mathbf{1}}\right]}\end{array}$ & $\boldsymbol{R}^{\mathbf{2}}$ \\
\hline $\mathrm{SBR}$ & 0.0480 & 0.9539 & 50.329 & 0.9121 \\
\hline $\mathrm{NR}$ & 0.0352 & 0.8011 & 38.685 & 0.7924 \\
\hline $\mathrm{EPDM}$ & 0.0353 & 0.6889 & 35.913 & 0.7381 \\
\hline $\mathrm{ENR}$ & 0.0174 & 0.7628 & 15.044 & 0.7846 \\
\hline $\mathrm{ZnO}$ & 0.1092 & 0.9387 & 241.96 & 0.7982 \\
\hline $\mathrm{ZnO} / \mathrm{SBR}$ & 0.0674 & 0.8813 & 94.625 & 0.7708 \\
\hline $\mathrm{ZnO} / \mathrm{NR}$ & 0.0208 & 0.4594 & 60.536 & 0.9035 \\
\hline $\mathrm{ZnO} / \mathrm{EPDM}$ & 0.0283 & 0.6850 & 19.289 & 0.4545 \\
\hline $\mathrm{ZnO} / \mathrm{ENR}$ & 0.0468 & 0.8323 & 30.785 & 0.7576 \\
\hline
\end{tabular}

$\mathrm{ZnO}$ powder gives the fastest photocatalytic degradation of $\mathrm{MB}$ followed by $\mathrm{ZnO} /$ rubbers and virgin rubbers. The degradation kinetics of $\mathrm{MB}$ for $\mathrm{ZnO} / \mathrm{SBR}$ was best fitted with the pseudo first order while for $\mathrm{ZnO} / \mathrm{NR}, \mathrm{ZnO} / \mathrm{EPDM}$ and $\mathrm{ZnO} / \mathrm{ENR}$ with pseudo second order equation. The rate constant of $\mathrm{ZnO} /$ SBR is $0.06740 \mathrm{~min}^{-1}$ which is the closest to $\mathrm{ZnO}$ $\left(0.1092 \mathrm{~min}^{-1}\right)$. Thus, it could be suggested that SBR is a promising substrate with excellent photosensitizer property than ENR, NR and EPDM.

\section{Conclusions}

The present study outlines a simple and fast method for the mechanical preparation of photocatalyst $\mathrm{ZnO}$ with SBR, NR, EPDM, and ENR as photosensitizer substrates to overcome loose powder after degradation process. The $\mathrm{ZnO}$ reveals hexagonal wurtzite structure with irregular shaped surfaces and agglomerates. $\mathrm{ZnO}$ photocatalyst shows the highest photocatalytic activity as compared to $\mathrm{ZnO} /$ rubbers and virgin rubbers. Surprisingly, the degradation of $\mathrm{MB}$ for $\mathrm{ZnO} / \mathrm{SBR}$ is $72.89 \%$ the most comparable to $\mathrm{ZnO}$, $87.32 \%$. The kinetic degradation of $\mathrm{MB}$ for $\mathrm{ZnO}$, $\mathrm{ZnO} / \mathrm{SBR}$ and virgin rubbers were best fitted with the pseudo-first-order, while $\mathrm{ZnO} / \mathrm{NR}, \mathrm{ZnO} / \mathrm{EPDM}$ and $\mathrm{ZnO} / \mathrm{ENR}$ with the pseudo-second-order.

\section{Acknowledgements}

The authors would like to thank Faculty of Applied Sciences, Universiti Teknologi MARA, Shah Alam, Selangor for facilitating this work.

\section{References}

[1] Mendoza-Damián G., Tzompantzi F., Mantilla A., Pérez-Hernández R., Hernández-Gordillo A.: Improved photocatalytic activity of $\mathrm{SnO}_{2}-\mathrm{ZnAl} \mathrm{LDH}$ prepared by one step $\mathrm{Sn}^{4+}$ incorporation. Applied Clay Science, 121-122, 127-136 (2016). https://doi.org/10.1016/j.clay.2015.12.007

[2] Bandekar G., Rajurkar N. S., Mulla I. S., Mulik U. P., Amalnekar D. P., Adhyapak P. V.: Synthesis, characterization and photocatalytic activity of PVP stabilized $\mathrm{ZnO}$ and modified $\mathrm{ZnO}$ nanostructures. Applied Nanoscience, 4, 199-208 (2012).

https://doi.org/10.1007/s13204-012-0189-2

[3] Adeleke J. T., Theivasanthi T., Thiruppathi M., Swaminathan M., Akomolafe T., Alabi A. B.: Photocatalytic degradation of methylene blue by $\mathrm{ZnO} / \mathrm{NiFe}_{2} \mathrm{O}_{4}$ nanoparticles. Applied Surface Science, 455, 195-200 (2018).

https://doi.org/10.1016/j.apsusc.2018.05.184

[4] Chen X., Wu Z., Liu D., Gao Z.: Preparation of ZnO photocatalyst for the efficient and rapid photocatalytic degradation of azo dyes. Nanoscale Research Letters, 12, 143/1-143/10 (2017). https://doi.org/10.1186/s11671-017-1904-4

[5] Irani M., Mohammadi T., Mohebbi S.: Photocatalytic degradation of methylene blue with $\mathrm{ZnO}$ nanoparticles; A joint experimental and theoretical study. Journal of the Mexican Chemical Society, 60, 218-225 (2016). https://doi.org/10.29356/jmcs.v60i4.115

[6] Alenezi M. R., Alshammari A. S., Jayawardena K. D. G. I., Beliatis M. J., Henley S. J., Silva S. R. P.: Role of the exposed polar facets in the performance of thermally and UV activated $\mathrm{ZnO}$ nanostructured gas sensors. The Journal of Physical Chemistry, 117, 17850-17858 (2013). https://doi.org/10.1021/jp4061895

[7] Xiao Y., Lu L., Zhang A., Zhang Y., Sun L., Huo L., Li F.: Highly enhanced acetone sensing performances of porous and single crystalline $\mathrm{ZnO}$ nanosheets: High percentage of exposed (100) facets working together with surface modification with Pd nanoparticles. ACS Applied Materials Interfaces, 4, 3797-3804 (2012). https://doi.org/10.1021/am3010303

[8] Johar M. A., Afzal R. A., Alazba A. A., Manzoor U.: Photocatalysis and bandgap engineering using $\mathrm{ZnO}$ nanocomposites. Advances in Materials Science Engineering, 2015, 934587/1-934587/22 (2015). https://doi.org/10.1155/2015/934587

[9] Ismail W. I. N. W., Ain S. K., Zaharudin R., Jawad A. H., Ishak M. A. M., Ismail K., Sahid S.: New $\mathrm{TiO}_{2} /$ DSAT immobilization system for photodegradation of anionic and cationic dyes. International Journal of Photoenergy, 2015, 232741/1-232741/6 (2015). https://doi.org/10.1155/2015/232741 
[10] Dzinun H., Othman M. H. D., Ismail A. F., Puteh M. H., Rahman M. A., Jaafar J.: Photocatalytic degradation of nonylphenol by immobilized $\mathrm{TiO}_{2}$ in dual layer hollow fibre membranes. Chemical Engineering Journal, 269, 255-261 (2015).

https://doi.org/10.1016/j.cej.2015.01.114

[11] Wang W., Ai T., Yu Q.: Electrical and photocatalytic properties of boron-doped $\mathrm{ZnO}$ nanostructure grown on PET-ITO flexible substrates by hydrothermal method. Scientific Reports, 7, 42615/1-42615/11 (2017).

https://doi.org/10.1038/srep42615

[12] Parada-Gamboa N. J., Pedraza-Avella J. A., Meléndez A. M.: Effect of substrate surface treatment on electrochemically assisted photocatalytic activity of N-S codoped $\mathrm{TiO}_{2}$ films. Journal of Physics: Conference Series, 786, 012045/1-012045/6 (2017).

https://doi.org/10.1088/1742-6596/786/1/012045

[13] Sriwong C., Wongnawa S., Patarapaiboolchai O.: Recyclable thin $\mathrm{TiO}_{2}$-embedded rubber sheet and dye degradation. Chemical Engineering Journal, 191, 210 217 (2012).

https://doi.org/10.1016/j.cej.2012.03.005

[14] Huo P., Yan Y., Li S., Li H., Huang W.: Floating photocatalysts of fly-ash cenospheres supported $\mathrm{AgCl} / \mathrm{TiO}_{2}$ films with enhanced Rhodamine B photodecomposition activity. Desalination, 256, 196-200 (2010).

https://doi.org/10.1016/j.desal.2010.01.012

[15] Xue H., Jiang Y., Yuan K., Yang T., Hou J., Cao C., Feng K., Wang X.: Floating photocatalyst of B-N-TiO $2 /$ expanded perlite: A sol-gel synthesis with optimized mesoporous and high photocatalytic activity. Scientific Reports, 6, 29902/1-29902/9 (2016).

https://doi.org/10.1038/srep29902

[16] Jawad A. H., Mubarak N. S. A., Ishak M. A. M., Ismail K., Nawawi W. I.: Kinetics of photocatalytic decolourization of cationic dye using porous $\mathrm{TiO}_{2}$ film. Journal of Taibah University for Science, 10, 352-362 (2016). https://doi.org/10.1016/j.jtusci.2015.03.007

[17] Selvam V., Kumar P. S., Krishnan G. N., Andavan G. T. S.: Photocatalytic degradation of organic contaminants by $g-\mathrm{C}_{3} \mathrm{~N}_{4} / \mathrm{EPDM}$ nanocomposite film: Viable, efficient and facile recoverable. Materials Science and Engineering C, 84, 188-194 (2018).

https://doi.org/10.1016/j.msec.2017.11.039

[18] de Filpo G., Pantuso E., Armentano K., Formoso P., di Profio G., Poerio T., Fontananova E., Meringolo C., Mashin A. I., Nicoletta F. P.: Chemical vapor deposition of photocatalyst nanoparticles on PVDF membranes for advanced oxidation processes. Membranes, 8, 35/135/15 (2018).

https://doi.org/10.3390/membranes8030035

[19] Zargazi M., Entezari M. H.: Anodic electrophoretic deposition of $\mathrm{Bi}_{2} \mathrm{WO}_{6}$ thin film: High photocatalytic activity for degradation of a binary mixture. Applied Catalysis B: Environmental, 242, 507-517 (2018). https://doi.org/10.1016/j.apcatb.2018.09.093
[20] Verma H. K., Rehani D., Sharma S. N., Maurya K. K.: Synthesized zinc oxide nano rods and flowers studies for optical, di-electrical and photocatalytic applications. Optik, 204, 164154/1-164154/6 (2020).

https://doi.org/10.1016/j.ijleo.2019.164154

[21] Varshney G., Kanel S. R., Kempisty D. M., Varshney V., Agrawal A., Sahle-Demessie E., Varma R. S., Nadagouda M. N.: Nanoscale $\mathrm{TiO}_{2}$ films and their application in remediation of organic pollutants. Coordination Chemistry Reviews, 306, 43-64 (2016).

https://doi.org/10.1016/j.ccr.2015.06.011

[22] Arakha M., Roy J., Nayak P. S., Mallick B., Jha S.: Zinc oxide nanoparticle energy band gap reduction triggers the oxidative stress resulting into autophagy-mediated apoptotic cell death. Free Radical Biology and Medicine, 110, 42-53 (2017).

https://doi.org/10.1016/j.freeradbiomed.2017.05.015

[23] Nucciarelli F., Bravo I., Catalan-Gomez S., Vázquez L., Lorenzo E., Pau J. L.: High ultraviolet absorption in colloidal gallium nanoparticles prepared from thermal evaporation. Nanomaterials, 7, 172/1-172/12 (2017). https://doi.org/10.3390/nano7070172

[24] Lavand A. B., Malghe Y. S.: Synthesis, characterization and visible light photocatalytic activity of nitrogendoped zinc oxide nanospheres. Journal of Asian Ceramic Societies, 3, 305-310 (2015). https://doi.org/10.1016/j.jascer.2015.06.002

[25] Ahmed M. A., Kandil U. F., Shaker N. O., Hashem A. I.: The overall effect of reactive rubber nanoparticles and nano clay on the mechanical properties of epoxy resin. Journal of Radiation Research and Applied Sciences, 8, 549-561 (2015). https://doi.org/10.1016/j.jrras.2015.06.010

[26] Manohar N., Jayaramudu J., Suchismita S., Rajkumar K., Reddy A. B., Sadiku E. R., Priti R., Maurya D. J.: A unique application of the second order derivative of FTIR-ATR spectra for compositional analyses of natural rubber and polychloroprene rubber and their blends. Polymer Testing, 62, 447-453 (2017).

https://doi.org/10.1016/j.polymertesting.2017.07.030

[27] Mokhothu T. H., Luyt A. S., Messori M.: Reinforcement of EPDM rubber with in situ generated silica particles in the presence of a coupling agent via a sol-gel route. Polymer Testing, 33, 97-106 (2014). https://doi.org/10.1016/j.polymertesting.2013.11.009

[28] Mahmood W. A. K., Khan M. M. R., Azarian M. H.: Sol-gel synthesis and morphology, thermal and optical properties of epoxidized natural rubber/zirconia hybrid films. Journal of Non-Crystalline Solids, 378, 152-157 (2013).

https://doi.org/10.1016/j.jnoncrysol.2013.07.002

[29] Ismail H., Nordin R.: Effect of epoxidized natural rubber (ENR) and ethylene-co-acrylic acid copolymer on properties of silica-filled natural rubber/recycle rubber powder blends. Polymer-Plastics Technology and Engineering, 43, 285-300 (2004). https://doi.org/10.1081/PPT-120029964 
[30] Danna C. S., Cavalcante G. S. M., Gomes A. S., KercheSilva L. E., Yoshihara E., Osorio-Roman I. O., Salmazo L. O., Rodríguez-Perez M. A., Aroca R. F., Job A. E.: Silver nanoparticles embedded in natural rubber films: Synthesis, characterization, and evaluation of in vitro toxicity. Journal of Nanomaterials, 2016, 2368630/12368630/10 (2016).

https://doi.org/10.1155/2016/2368630

[31] Al-Kadhemy M. F. H., Hussein R., Al-Zuky A. A. D.: Analysis of the absorption spectra of styrene-butadiene in toluene. Journal of Physical Science, 23, 89-100 (2012).

https://jps.usm.my/analysis-absorption-spectra-styrenebutadiene-toluene/

[32] Kumar H., Rani R.: Structural and optical characterization of $\mathrm{ZnO}$ nanoparticles synthesized by microemulsion route. International Letters of Chemistry, Physics and Astronomy, 19, 26-36 (2013).

https://doi.org/10.18052/www.scipress.com/ILCPA.19.26
[33] Li X., McNaughter P. D., O’Brien P., Minamimoto H., Murakoshi K.: Plasmonically enhanced electromotive force of narrow bandgap PBS QD-based photovoltaics. Physical Chemistry Chemical Physics, 20, 14818 14827 (2018). https://doi.org/10.1039/C8CP00767E

[34] Shoueir K., Kandil S., El-Hosainy H., El-Kemary M.: Tailoring the surface reactivity of plasmonic $\mathrm{Au} @ \mathrm{TiO}_{2}$ photocatalyst bio-based chitosan fiber towards cleaner of harmful water pollutants under visible-light irradiation. Journal of Cleaner Production, 230, 383-393 (2019). https://doi.org/10.1016/j.jclepro.2019.05.103

[35] Jin Z., Zhang Q., Chen J., Huang S., Hu L., Zeng Y-J., Zhang H., Ruan S., Ohno T.: Hydrogen bonds in heterojunction photocatalysts for efficient charge transfer. Applied Catalysis B: Environmental, 234, 198-205 (2018). https://doi.org/10.1016/j.apcatb.2018.04.057

[36] Alkhatib I. I., Garlisi C., Pagliaro M., Al-Ali K., Palmisano G.: Metal-organic frameworks for photocatalytic $\mathrm{CO}_{2}$ reduction under visible radiation: A review of strategies and applications. Catalysis Today, 340, 209-224 (2020). https://doi.org/10.1016/j.cattod.2018.09.032 